\title{
Health Disparities in the Border Region: A Course-based Undergraduate Research Experience (CURE) with Concomitant Civic Engagement Education
}

\author{
Aimee Hernandez and Jeffrey T. Olimpo
}

The University of Texas at El Paso, Biological Sciences, 500 W. University Ave, B226 Biology Bldg, El Paso TX 79968 USA

(aahernandez18@miners.utep.edu)

\begin{abstract}
Course-based undergraduate research experiences (CUREs) seek to engage students in the authentic process of scientific discovery. Current evidence in the literature suggests that participation in CUREs results in significant increases in students' development of scientific reasoning skills and experimental design abilities. While these outcomes are noteworthy, relatively few studies have examined and assessed potential mechanisms for connecting student-initiated research endeavors within CURE contexts to the broader community. In order to address these concerns, we conducted a quasi-experimental, mixed methods study to evaluate the impact of a civic engagementinfused "Health Disparities in the Border Region" CURE on students' $(n=17)$ development of public outreach skills, researcher self-efficacy, and understanding of research-community connections. Results indicated a significant, pre/post-semester increase in students' ability to identify and describe the relationship between components of a public health outreach plan ( $\mathrm{p} \leq 0.039$ for all analyses), as measured via the Public Health Outreach Flowchart assessment. Analysis of student responses to the Persistence in the Sciences (PITS) questionnaire further revealed a positive, pre/post-semester shift in participants' researcher self-efficacy $(\mathrm{p}=0.004)$, with students $(68.8 \%)$ noting the importance of their research in engaging the public around relevant healthcare issues within the community.
\end{abstract}

Keywords: CURE assessment, civic engagement, public health outreach, Persistence in the Sciences

\section{Mission, Review Process \& Disclaimer}

The Association for Biology Laboratory Education (ABLE) was founded in 1979 to promote information exchange among university and college educators actively concerned with teaching biology in a laboratory setting. The focus of ABLE is to improve the undergraduate biology laboratory experience by promoting the development and dissemination of interesting, innovative, and reliable laboratory exercises. For more information about ABLE, please visit http://www.ableweb.org/.

Advances in Biology Laboratory Education is the peer-reviewed publication of the conference of the Association for Biology Laboratory Education. Published articles and extended abstracts are evaluated and selected by a committee prior to presentation at the conference, peer-reviewed by participants at the conference, and edited by members of the ABLE Editorial Board. Published abstracts are evaluated and selected by a committee prior to presentation at the conference.

\section{Citing This Article}

Hernandez A, Olimpo JT. 2020. Health disparities in the border region: a course-based undergraduate research experience (CURE) with concomitant civic engagement education. Article 72 In: McMahon K, editor. Advances in biology laboratory education. Volume 41. Publication of the 41st Conference of the Association for Biology Laboratory Education (ABLE). https://doi.org/10.37590/able.v41.abs72

Compilation (C) 2020 by the Association for Biology Laboratory Education, ISBN 1-890444-17-0. All rights reserved. Nopart of this publication may be reproduced, stored in a retrieval system, or transmitted, in any form or by any means, electronic, mechanical, photocopying, recording, or otherwise, without the prior written permission of the copyright owner. 
ABLE strongly encourages individuals to use the exercises in this volume in their teaching program. If this exercise is used solely at one's own institution with no intent for profit, it is excluded from the preceding copyright restriction, unless otherwise noted on the copyright notice of the individual chapter in this volume. Proper credit to this publication must be included in your laboratory outline for each use; a sample citation is given above. 